\title{
Forecasting on China’s Total Water Demand in 2018
}

\author{
Xiuli Liu \\ Academy of Mathematics and Systems Science, Chinese Academy of Sciences, Zhongguancun East Road No.55, Beijing, P.R. \\ China, 100190 \\ University of Chinese Academy of Sciences Beijing, 19 A Yuquan Rd, Shijingshan District, Beijing, P.R. China 100049 \\ Center for Forecasting Science, Chinese Academy of Sciences, Beijing, P.R. China, 100190
}

\begin{abstract}
To forecast total water demand in advance is practically important for water supply planning. The paper first made impacting factors analysis of the total water demand in China. Then established three models for the total water demand forecasting by multiple regression analysis. The fitting precision of the forecasting models is satisfactory. Applied the models and expert experiences, made the total water demand forecast in China 2018 in some scenarios. The results show that the total water demand will be 608.04 billion $\mathrm{m}^{3}$ in 2018 in China.
\end{abstract}

Keywords-water demand; forecast; multiple regression analysis; combined forecasting model; China

\section{INTRODUCTION}

China is severely lack in water resources. Its water resources was only 2.8 trillion $\mathrm{m}^{3}$ in 2013 , accounting for about $6 \%$ of the world's total water resources, and average per capita water resources was less than $30 \%$ of the world average. However, in China since 2003 total water demand had been in a uptrend, China's total water demand was 554.8 billion $\mathrm{m}^{3}$ in 2004 which grew to 609.0 billion $\mathrm{m}^{3}$ in 2017. With China's economic development, on the one hand total water demand will continue to increase in the short term, on the other hand the negative effects of water shortages on economic development will also grow. It had been pointed out that water problems which was mainly water shortage would make economic growth rate decreased by $1 \%$ to $2 \%$ in China, higher than the impact of energy prices increase and a decline in foreign investment, and the water shortage had become an important factor restricting China's economic and social development, by RAND Corporation report ${ }^{[1]}$.

Currently, there are many researches on water demand. Sen et al (2009) established a fuzzy model for predicting daily

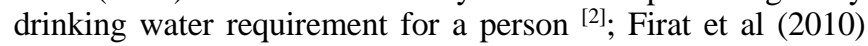
found CCNN model performed better than GRNN model and FFNN model by comparing the prediction effect of daily water demand in Izmir, Turkey ${ }^{[3]}$. Herrera et al (2010) made water demand prediction of a city in southeastern Spain, the results indicated SVM model had the highest prediction accuracy, followed by multivariate adaptive regression spline model, projection pursuit model, random forest model and neural network model [4]; Nasseri et al (2011) established a genetic algorithm model to predict urban water demand in Tehran ${ }^{[5]}$; Ajbar et al (2013) built a neural network model to forecast the monthly and annual water demand for Mecca city, Saudi Arabia [6]. These forecasting methods mainly are neural network model (ANNs), fuzzy systems theory model, projection pursuit model and genetic algorithms, or improved model and combined model. However, these models generally do not have high prediction accuracy, whose errors are usually higher than 5\%, and are not conducive to analyze how the factors affect the water demand ${ }^{\text {[2- }}$ $6]$.

Researches inside China mainly apply multivariate prediction model ${ }^{[7-8]}$ and models considering the inherent law of water use and time trend ${ }^{[9-13]}$. Liu et al (2012) applied gray linear combination forecast model to predict residential domestic water consumption in Baotou city, and the combined forecast model performed better than the single model [7]; Wang et al (2012) combined stepwise regression and partial least squares to predict water demand, and the results showed the combined forecast model performed better ${ }^{[8]}$; For models considering the inherent law of water use and time trend, mainly are gray model, ANNs, SVM, genetic algorithm model, time series models and exponential smoothing models, such as Shu et al (2009), Zhang et al (2009), Li et al (2010); Zai et al (2009) chose radial basis function as the kernel function and established a least squares

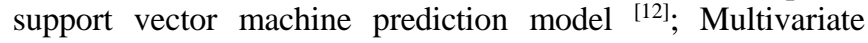
prediction model not only better interprets how water consumption changes but also have higher prediction accuracy and its forecasting error generally less than 3\%. While the error of models which only consider the inherent law of water use and time trends was generally higher than $5 \%$.

In this paper, multivariate prediction model was chosen to predict total water demand for China. On the basis of comprehensive impacting factors analysis of the total water demand, three water demand forecast models were built to predict 2018 total water demand in China.

\section{MAIN IMPACTING FACTORS ANALYSIS}

There are complicated and diversified influence factors of the total water demand, such as demographic, grain yield, the level of economic development, industrial structure and water price and so on. The correlation analysis was made for some main factors.

\section{A. Population}

The total water consumption especially domestic water consumption is directly connected with population. On the one hand, if the per capita domestic water consumption unchanged, domestic water consumption linearly will grow as the population grows. On the other hand, with the improvement of living standards, per capita domestic water consumption is growing and domestic water consumption growth will be larger than the population growth. Figure 1 shows the trends of domestic water consumption and population in China in 2000-2017, from 20002011, domestic water consumption increased while population increased year by year. Total domestic water consumption 
decreased in 2012 because from the year livestock water consumption original as a part of domestic water consumption is classified to agriculture water consumption.

\section{B. National Grain Yield}

In China, agriculture water consumption accounts for a high proportion of the total water consumption. In 2017, agriculture water consumption was 379.03 billion $\mathrm{m}^{3}$, accounted for $62.2 \%$ of the total water consumption. During the past years 2000-2017, the proportion of agriculture water consumption was in the range $61 \%-65 \%$. Agriculture water consumption is directly connected with grain yield. Figure 2 shows their trends. By calculation, the correlation coefficient between them was 0.83 in China during 1959-2017, which was a significant positive correlation.

\section{Change of Industrial Structure}

Since 2003, with the acceleration of the industrialization process, the proportion of the value added of the secondary and tertiary industries accounted for GDP basically showed a gradual increasing trend (Figure 3). From the perspective of the industrial water use efficiency, the water use by one hundred million Yuan of industrial value added is significantly lower than those of agriculture (Figure 4). Decreasing the proportion of value added of agriculture will decrease the total water demand, which indicates the change of industrial structure is another major impacting factor.

In addition to population, the national grain output and industrial structure changes which were analyzed in this section, some other researches ${ }^{[6,13]}$ also showed that GDP, GDP per capita ${ }^{[14-16]}$ and so on are also closely related to the total water consumption, and here we made no longer analysis one by one.

\section{FORECASTING MODELS}

Based on the analysis of impacting factors, the initially selected factors of total water consumption in this paper were population, grain yield, the proportion of secondary industry and tertiary industry accounted for GDP, GDP per capita and GDP. The sample periods are 1980, 1990, 1993, 1995 and 1997-2017 years. Establishing the regression model by random combination of these impacting factors, finally three prediction models were chosen according to statistical test indicators and rational economic explanation of the model.

$$
\begin{aligned}
& \hat{Y}=2995.59+4.10 \times 10^{-3} X_{1}+19.03 \times 10^{-3} X_{2}+87.49 \times 10^{-3} X_{3}-1.1 \times 10^{-6} X_{3}{ }^{2}(1) \\
& t=(3.65) \\
& R^{2}=0.979 \text {, adjusted } R^{2}=0.974, D . W=1.877 \\
& \hat{Y}=-1780.82+43.30 \times 10^{-3} X_{2}+6160.63 X_{4}-290.25 \times 10^{-3} X_{5}+61.96 \times 10^{-3} Y(-1) \\
& t=(-0.79) \\
& R^{2}=0.962 \text {, adjusted } R^{2}=0.949, D . W=1.675 \\
& \hat{Y}=-1807.60+42.32 \times 10^{-3} X_{2}-4.30 \times 10^{-7} X_{3}{ }^{2}+5904.22 X_{4}+69.31 \times 10^{-3} Y(-1)(3) \\
& t=(-0.82) \quad(3.49) \quad(-0.66) \quad(3.00) \quad(0.36) \\
& R^{2}=0.962 \text {, adjusted } R^{2}=0.949, D . W=1.687
\end{aligned}
$$

Where $\hat{Y}$ is fitted value of the total water consumption and its unit is one hundred million $\mathrm{m}^{3}$; $\mathrm{Y}(-1)$ means the total water consumed last year and the unit is one hundred million $\mathrm{m}^{3} ; \mathrm{X}_{1}$ means population, the unit is ten thousand persons; $X_{2}$ means national grain yield whose unit is ten thousand tons; $\mathrm{X}_{3}$ stands for GDP and the unit is one hundred million Yuan, in comparable price of $1980 ; \mathrm{X}_{4}$ means the proportion of value added of secondary and tertiary industries accounted for the GDP; $\mathrm{X}_{5}$ indicates GDP per capita and the unit is Yuan per person, in comparable price of 1980; The datum of the total water consumption in 1980 is from China Water Consumption (published in 1989), the data in 1990, 1993 and 1995 is from China's Water Supply and Demand in $21^{\text {st }}$ century (published in 1999), the data of the total water consumption between 20002016 is from China Water Resources Bulletin (published 20002016); other data come from China Statistical Yearbook and CEIC database. As we can see from models (1)-(3), every adjusted R-squared is high, which indicates the overall fitting effect is well, and the value of D.W indicates the correlation of random disturbance sequence does not exist.

\section{Models Application}

The total water demand in 2018 is forecasted by applying models (1)-(3). The values of the main variables in the models were assumed in advance. It is assumed an increase of about 11.7 million populations in 2018 in China. It is supposed that the national grain output would be 618.4 million tons in 2018 in China. China's economic growth would be $6.7 \%$ in 2018 , where the growth of value added of three industries would be $3.9 \%, 7.1 \%$ and $8.0 \%$ respectively. With the hypothesis, applied models (1)-(3), the forecasting results are shown in Table 1.

As each model considered different impacting factors, the results have slight differences. For these models did not consider the impact of water conservation policies, measures and climate changes separately for data limitation, the forecasting results were adjusted with expert empirical method. The total water demand is expected to be 608.04 billion $\mathrm{m}^{3}$ in 2018 in China.

\section{CONCLUSION}

With the experience on forecasting errors and data demand of previous water demand prediction models, the paper made impacting factors analysis of the total water demand in China and established multi-factor prediction models for China total water demand. In some scenario hypothesis for population, grain yield and economic growth, with models (1)-(3) and expert experiences, the total water demand in China in 2018 is forecasted to be 608.04billion $\mathrm{m}^{3}$.

TABLE I. FORECASTING RESULTS ON THE TOTAL WATER DEMAND IN 2018 (UNIT: BILLION M³)

\begin{tabular}{|c|c|c|}
\hline Model 1 & Model 2 & Model 3 \\
\hline 618.75 & 612.00 & 604.46 \\
\hline
\end{tabular}




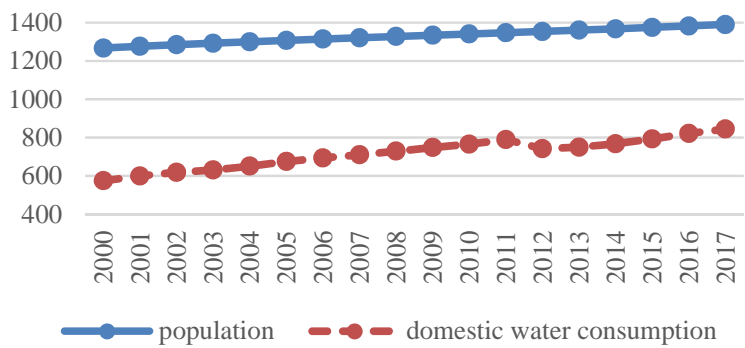

FIGURE I. TRENDS OF DOMESTIC WATER CONSUMPTION (100 MILLION M3) AND POPULATION (MILLION) IN CHINA DURING 1997-2017
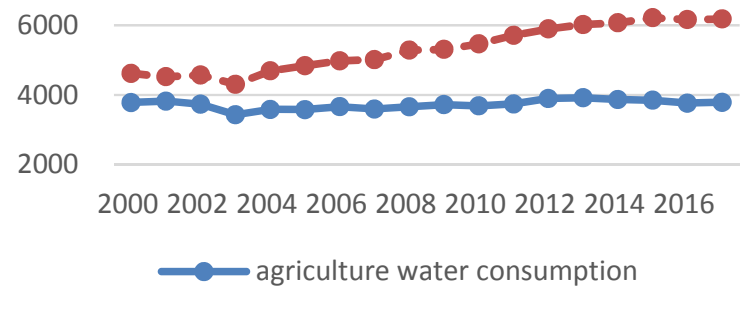

- national grain output

FIGURE II. TRENDS OF AGRICULTURE WATER CONSUMPTION (UNIT: 100 MILLION M3) AND NATIONAL GRAIN OUTPUT (UNIT: 10000 TONS) IN CHINA

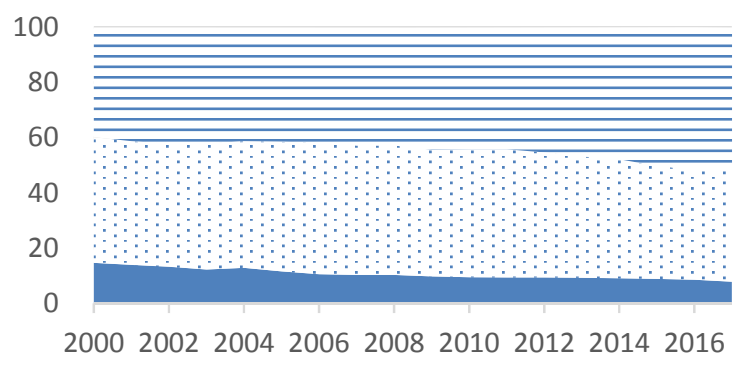

a The primary industry $\quad:$ T The secondary industry

$=$ The tertiary industry

FIGURE III. TRENDS OF THREE INDUSTRIAL STRUCTURE CHANGE IN CHINA

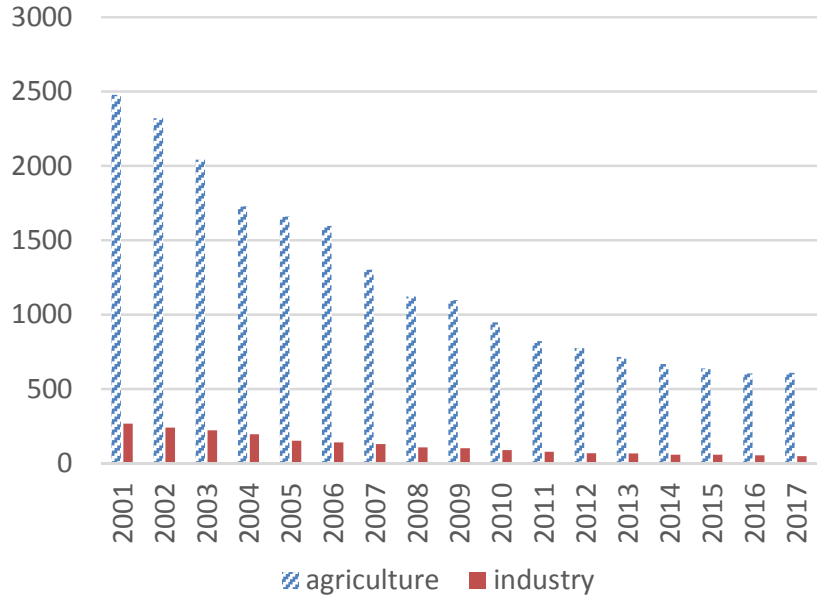

FIGURE IV. WATER USE BY ONE HUNDRED MILLION YUAN OF AGRICULTURAL AND INDUSTRIAL VALUE ADDED IN CHINA (NOTE: VALUE ADDED CALCULATED IN ACCORDANCE WITH COMPARABLE PRICES IN 2003)

\section{ACKNOWLEDGMENT}

The author would like to acknowledge the support from the National Natural Science Foundation of China (No.71173210).

\section{REFERENCES}

[1] RAND. China's Continued Economic Progress: Possible Adversities and Obstacles. Paper presented at Beijing :5th Annual CRF-RAND Conference, Beijing, October 2002.

[2] Sen Z, \& Altunkaynak, A Fuzzy system modelling of drinking water consumption prediction. Expert Systems with Applications, 2009, 36, pp.11745-11752.

[3] Firat M, Turan M E, \& Yurdusev M A. Comparative analysis of neural network techniques for predicting water consumption time series. Journal of Hydrology, 2010, 384, pp.46-51.

[4] Herrera M, Torgo L, Izquierdo J, \& Perez-Garcia R. Predictive models for forecasting hourly urban water demand. Journal of Hydrology, 2010, 387, pp. 141-150.

[5] Nasseri M, Moeini A, \& Tabesh M. Forecasting monthly urban water demand using Extended Kalman Filter and Genetic Programming. Expert Systems with Applications, 2011, 38, pp.7387-7395.

[6] Ajbar A H, \& Ali E M. Prediction of municipal water production in touristic Mecca City in Saudi Arabia using neural networks. Journal of King Saud University-Engineering Sciences., 2013.

[7] Liu ZX, Zhang X, \& Wang YH. Forecast of urban residential domestic water consumption in Baotou, Journal of Water Resources \& Water Engineering, 2012, 23, pp.67-70. (In Chinese)

[8] Wang S, \& Sun YF. Urban water consumption prediction based on a partial least-square model coupled with stepwise regression. Journal of Safety and Environment, 2012, 12, pp.170-173. (In Chinese)

[9] Shu SH, Xiang G, He WJ, Wu CG, Zhao M, \& Yuan YX. The application of gray model for mid and long term city water demand, Journal of Harbin Institute of Technology, 2009, 41, pp.85-87. (In Chinese)

[10] Zhang HW, Lu RQ , \& Niu ZG. Prediction method of urban daily water consumption based on fractional theory. Journal of Tianjin University , 2009, 42, pp.56-59. (In Chinese)

[11] Li KB, \& Chen SF. Robust control of the investment in urban water supply and demand system. Journal of System Science and Mathematical Science, 2010, pp. 22-32. (In Chinese)

[12] Zai SM, Guo DD, \& Wen J. A prediction of irrigation water in People's Victory Canal Irrigation District based on the least squares support vector machine model. China Rural Water and Hydropower, 2009, pp.49-51. (In Chinese) 
[13] Zuo QT. Interval S-model for forecasting per capita domestic water consumption. Journal of Hydraulic Engineering, 2008, 39, pp.351-354. (In Chinese)

[14] Zhang B, Liu XL, Understanding Water Consumption and Demand in China, Advanced Material Research (EI), 2014, Vols.955-959, pp.31553160.

[15] Zou QR, Liu XL, Research on industrial water demand forecasting model and its application in China, Applied Mechanics and Materials(EI), 2014, Vols. 675-677, pp.976-981.

[16] Liu XL, Geoffrey Hewings, Chen XK, Wang SY, A factor decomposing model on water use efficiency at sector level and its application in Beijing, Journal of Systems Science and Complexity, 2016, 29(2), pp.405 